\title{
Control of astigmatism in cataract surgery
}

\author{
NICHOLAS A P BROWN AND JOHN M SPARROW \\ From the Nuffield Laboratory of Ophthalmology, Walton Street, Oxford OX2 6AW
}

SUMmARY A study is reported on cataract surgery, with intraocular lens implant, with measurement of the preoperative astigmatism and of the postoperative astigmatism over 28 weeks. Nine interrupted $10 / 0$ nylon sutures are used to close a limbal section. Preoperative astigmatism is compensated for in the method of suturing by the placement of additional sutures. Postoperatively sutures are cut in line with the plus cylinder axis in eyes showing excessive astigmatism with the rule. Final postoperative astigmatism is controlled within $2.25 \mathrm{D}$ cyl. $68 \%$ of cases lie within $1.0 \mathrm{D}$ cyl with the rule to $1.0 \mathrm{D}$ cyl against the rule. The average case in which sutures are not cut is one having $1.51 \mathrm{D}$ cyl with the rule at one week postoperatively, declining to zero at approximately 12 weeks, and having a final value of $0.17 \mathrm{D}$ cyl against the rule. No significant change in cylinder is seen after 10 weeks. The final postoperative astigmatism is only weakly correlated with the preoperative astigmatism, showing that the surgical method is effective. The spherical equivalent error is shown to shift in the direction of myopia in the postoperative period.

Astigmatism in the operated eye with an intraocular lens implant is most undersirable, since it reduces the effectiveness of the procedure. It is therefore worthwhile with these eyes to have an operating method that minimises astigmatism, even though it requires more time and attention by the surgeon.

Several factors responsible for surgically induced astigmatism have been identified. The most significant factor is in the tightness of the section closure. ${ }^{12}$ A loosely closed section allows the cornea to flatten with reduced curvature in the vertical meridian (Fig. 1), causing astigmatism against the rule. If the section is closed tightly, it stretches the cornea vertically, increasing the curvature in the vertical meridian (Fig. 2 ) and causing astigmatism with the rule. ${ }^{3}$ Other factors which have been defined are the preoperative astigmatism ${ }^{i}$, the position, ${ }^{45}$ length, and shape of the section, and the method of suturing, ${ }^{26-11}$ the number of sutures, ${ }^{12} 13$ sideways misalignment of section closure, ${ }^{10}$ and the postoperative use of steroids. ${ }^{14}$ In theory the further the section is made from the optical zone of the cornea ${ }^{3}$ the less will inaccurate (over-loose or over-tight) suturing affect the astig-

Correspondence to Mr N A P Brown, FRCS. matism, and this is borne out in practice.$^{59}$ The longer the bite of each suture, the more will excessive tension in the suture affect the astigmatism. ${ }^{15}$ The intraocular pressure (IOP), when raised, is a possible factor causing stretching of the section.

With the information available from the literature and from our previous experience it has become

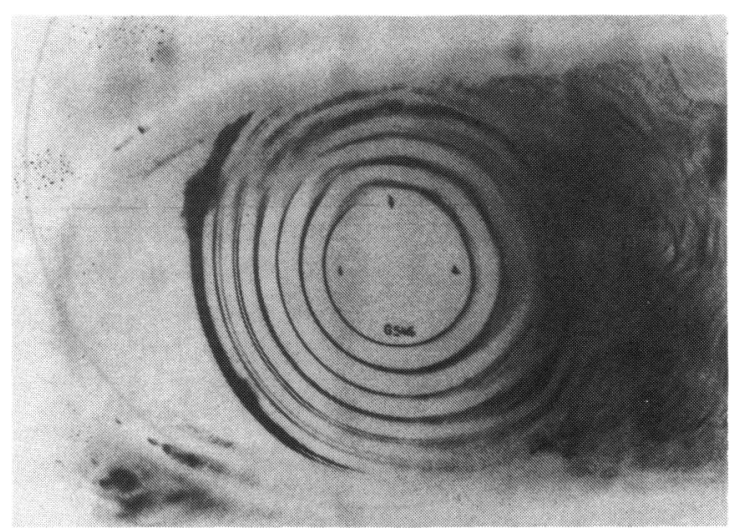

Fig. 1 Keratograph of an eye postoperatively showing 3.50 D cyl against the rule due to a loosely closed section. 


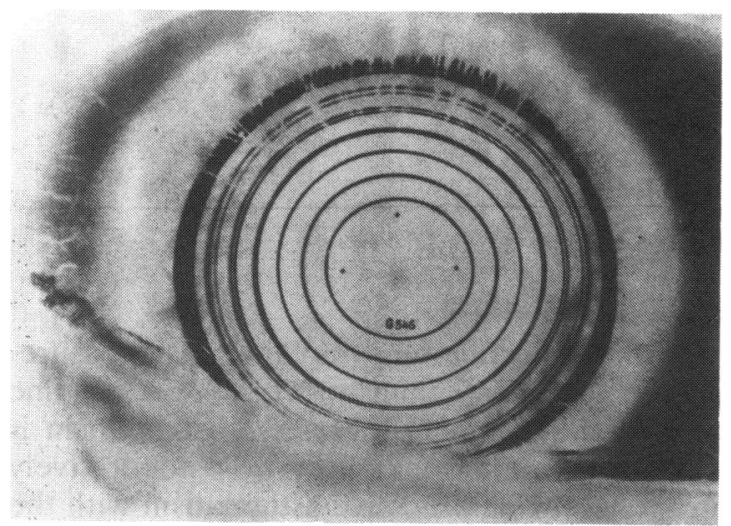

Fig. 2 Keratograph of an eye postoperatively showing 1.75 $D$ cyl with the rule. This is found to be the ideal initial postoperative result.

possible to design an effective method of section closure. Our previous experience was with interrupted virgin silk sutures with a limbal section and continuous (bootlace) nylon suture with a corneal section. The silk sutures produced initially a withthe-rule astigmatism, which gradually reduced to produce, all too often, a significant against-the-rule astigmatism on completion of healing. The continuous nylon suture produced an initial with-the-

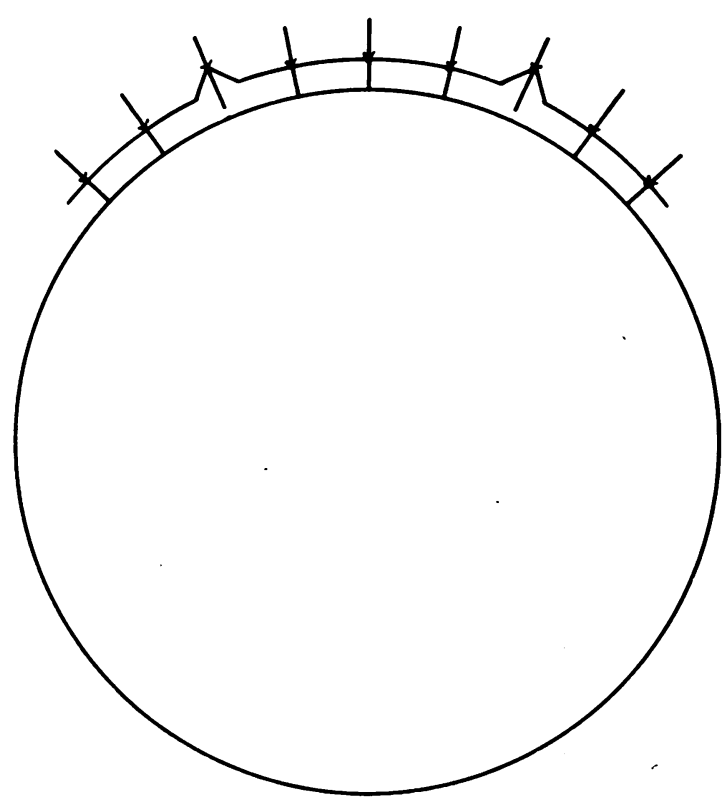

Fig. 3 The limbal section with two 'cat's ear' notches to ensure accurate repositioning. Nine interrupted $10 / 0$ nylon sutures are standard. rule astigmatism of a very variable amount. This showed less tendency to reduce with time, which has also been experienced by others. ${ }^{216}$ However, there were a few cases in which the continuous suture appeared to lose tension at about three weeks postoperatively, allowing the sudden development of against-the-rule astigmatism. The use of a keratometer in the operating theatre, ${ }^{14} 17-23$ prevents the cases of initial excessive with-the-rule astigmatism due to too tight a continuous suture, but it cannot guard against those cases that become slack subsequently, which would appear to be due to the interaction between the suture and the patient's tissue. We therefore concluded that interrupted sutures would be safer, since an individual suture becoming slack would not affect the entire section, and in addition these can be placed in a way to overcome the pre-existing astigmatism even when oblique.

Factors in postoperative astigmatism that we have not been able to take into account in the present study include tilt $^{24}$ and decentration of the lens implant. ${ }^{25}$

\section{Materials and methods}

\section{SELECTION OF PATIENTS}

One hundred consecutive eyes with cataract were included provided there was information on their previous refraction and the patients subsequently attended for follow-up to at least 22 weeks postoperatively. Ninety eyes received adequate followup and are reported on.

OPERATIVE METHOD

All eyes were operated on by the same technique. A limbus based conjunctival flap was followed by a 12 mm limbal section (Fig. 3) cut with a diamond and having two 'cat's ears' to half the corneoscleral depth. The 'cat's ears' ensure accurate repositioning of the section, and the first sutures are put in at these points. No preplaced sutures are used. The lens is extracted by the extracapsular method. After expression of the lens substance, one 10/0 nylon suture is inserted at the nasal 'cat's ear', prior to the aspiration of the remaining lens material and the insertion of a posterior chamber lens implant in the capsular sac. Sodium hyaluronate (Healonid) is used in all cases. The section is closed with interrupted $10 / 0$ nylon. The needle is first passed into the section on the scleral side and then through the surface on the corneal side (Figs. 4A, B), so that the knot is formed in the depth of the section. The overall distance of needle passage through the tissue is kept short $(1.4 \mathrm{~mm})$. A surgical knot is followed by a third tie and the ends are cut short. The basic number of sutures is nine. If the 


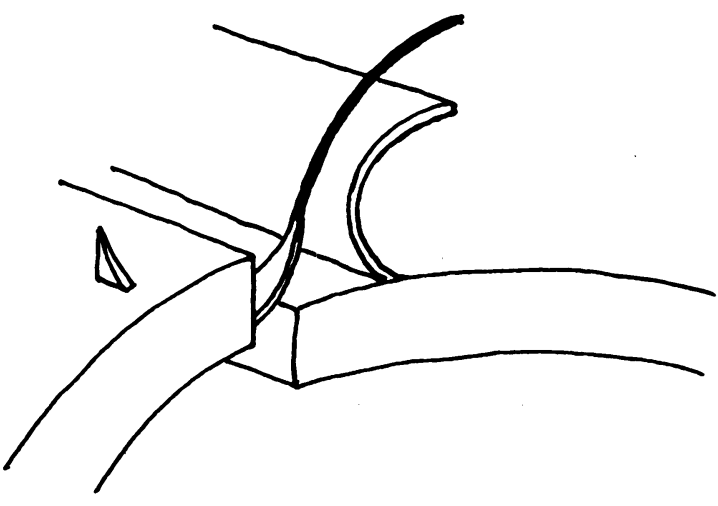

Fig. 4A

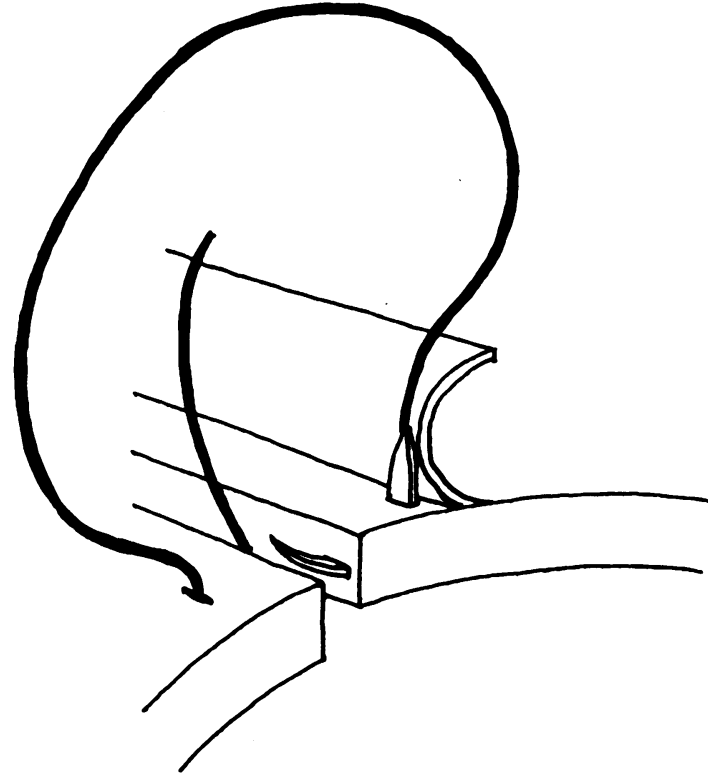

Fig. 4B

Fig. 4 A, B: The method of corneoscleral suturing to form a buried knot with 10/0 nylon.

patient had previously against-the-rue astigmatism, then additional sutures are added in line with the minus axis of the cylinder (Fig. 5). If the patient had previously with-the-rule astigmatism, the nine

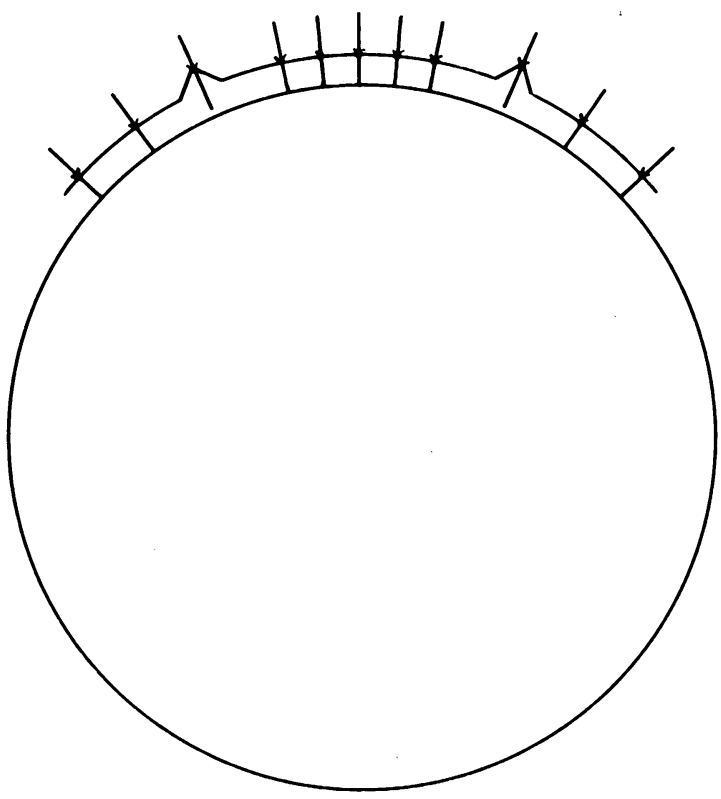

Fig. 5 Modified suturing to correct against-the-rule astigmatism by the insertion of additional sutures. sutures are used and tied less firmly. Overtight suture tying by this method is uncommon, since the initial turn on the knot will slip before the second turn is added. Oblique astigmatism is corrected by additional sutures in line with the minus axis of the pre-existing cylindrical correction (Fig. 6). Acetazolamide $500 \mathrm{mg}$ is given intravenously on completion of the operation.

\section{POSTOPERATIVE MANAGEMENT}

The patients received Maxitrol (neomycin, polymyxin B, dexamethasone) eye drops four times daily and Timoptol (timolol) eye drops $0.5 \%$ twice daily from the first postoperative day. The patients were seen at one week and two weeks postoperatively and then more variably, depending on individual needs at three, four, and six weeks, and then at longer intervals up to 22 weeks or longer. The patients were refracted and the applanation tension taken at each visit.

It was usual to find a with-the-rule astigmatism initially, which then declined. In patients showing a large initial with-the-rule astigmatic error of $+3.0 \mathrm{D}$ cyl or more, suture cutting was performed at one or two weeks postoperatively. When there was a persisting with-the-rule astigmatism of $2 \cdot 25 \mathrm{D}$ cyl or more at three weeks, suture cutting was initiated or further sutures cut in eyes that had already had sutures cut (Fig. 7). The procedure was continued up to six weeks, and in one case sutures were cut at 10 weeks. 


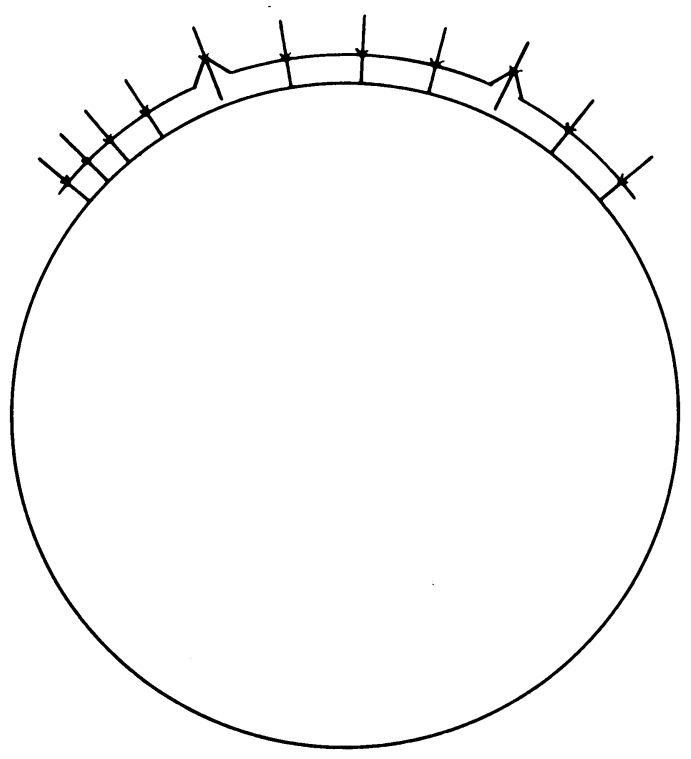

Fig. 6 Modified suturing to correct oblique astigmatism. In this case additional sutures are inserted to correct a preexisting minus cylindrical correction at $150^{\circ}$.

Individual sutures were cut at the slit-lamp microscope, the first suture cut being that in line with the plus cylinder axis. These patients then attended one week after suture cutting, when further sutures might be cut. The part of the suture that is cut is the most corneal limit of it. The corneal part of the suture then

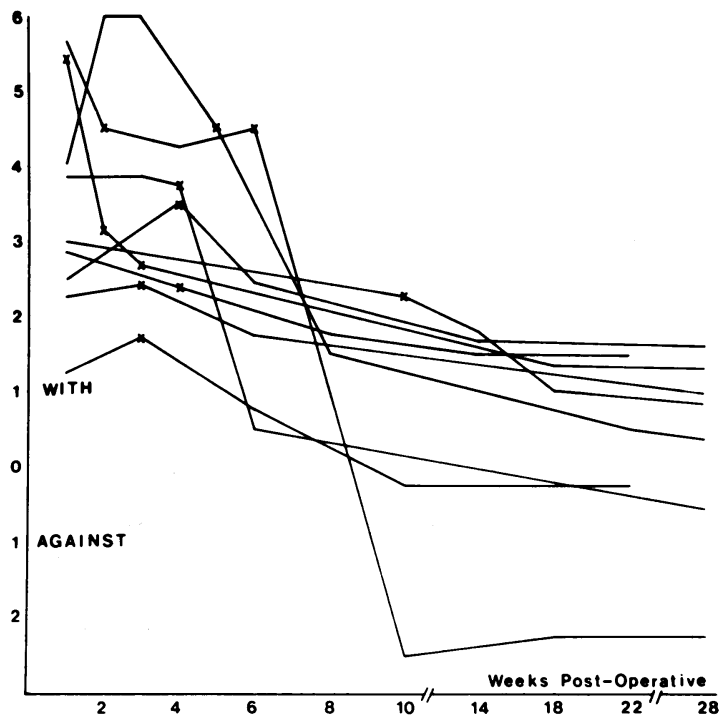

Fig. 7 Change in astigmatism in individual cases in which sutures cut. X marks the point in time when sutures cut. retracts into the cornea, and the scleral part remains lying flat under the conjunctiva; the suture does not need removing. The suture cutting procedure was used in nine eyes and would have been used in two others, but the patients were unable to attend in the appropriate period.

The applanation tension was taken at each visit. All eyes showing tensions over $20 \mathrm{mmHg}$ were continued on timolol eyedrops; otherwise the eyedrops given initially were stopped at one week. Maxitrol eyedrops were given four times a day for one month, twice daily for the next month, and daily for the following month.

\section{Results}

Pre- and postoperative astigmatic errors are considered to be with the rule when the plus correcting cylinder lies between $46^{\circ}$ and $135^{\circ}$, and against the rule when the plus correcting cylinder lies between $136^{\circ}$ and $45^{\circ}$.

Of the 90 eyes completing this study the greatest final cylindrical refractive errors were $2.25 \mathrm{D}$ with the rule and 2.25 against. $68 \%$ of the eyes had refractive errors within $1.00 \mathrm{D}$ with the rule to $1.00 \mathrm{D}$ against (Fig. 8). The distribution of final refractive errors was nearly even between with and against the rule (mean cylindrical error $0 \cdot 17 \mathrm{D}$ against the rule).

\section{CASES NOT REQUIRING SUTURE CUTTING}

Most of the patients had assessments at weeks 1, 3, 6, 10 , and 28. Some patients' visits did not conform to these precise times-for example, a patient may have been seen at week 8 or 12 . In such cases, in order to facilitate statistical analysis, linear interpolation was

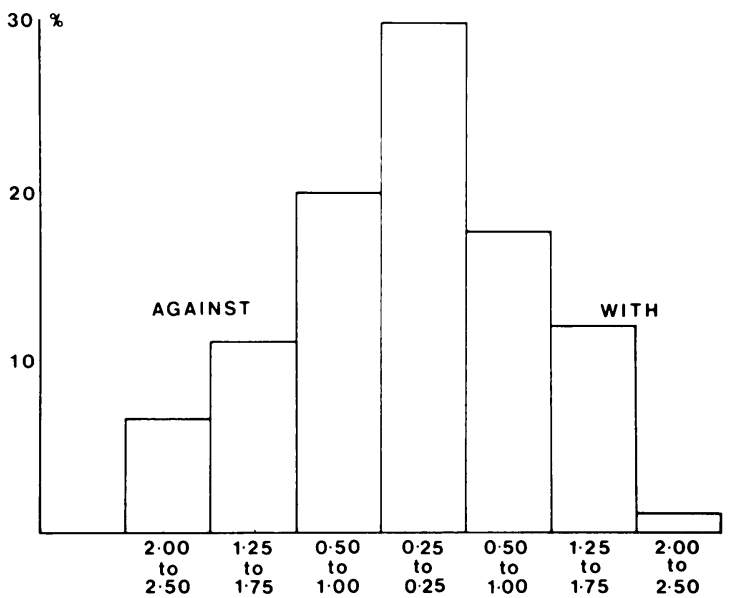

Fig. 8 Percentage distribution of final refractive errors (all cases). 


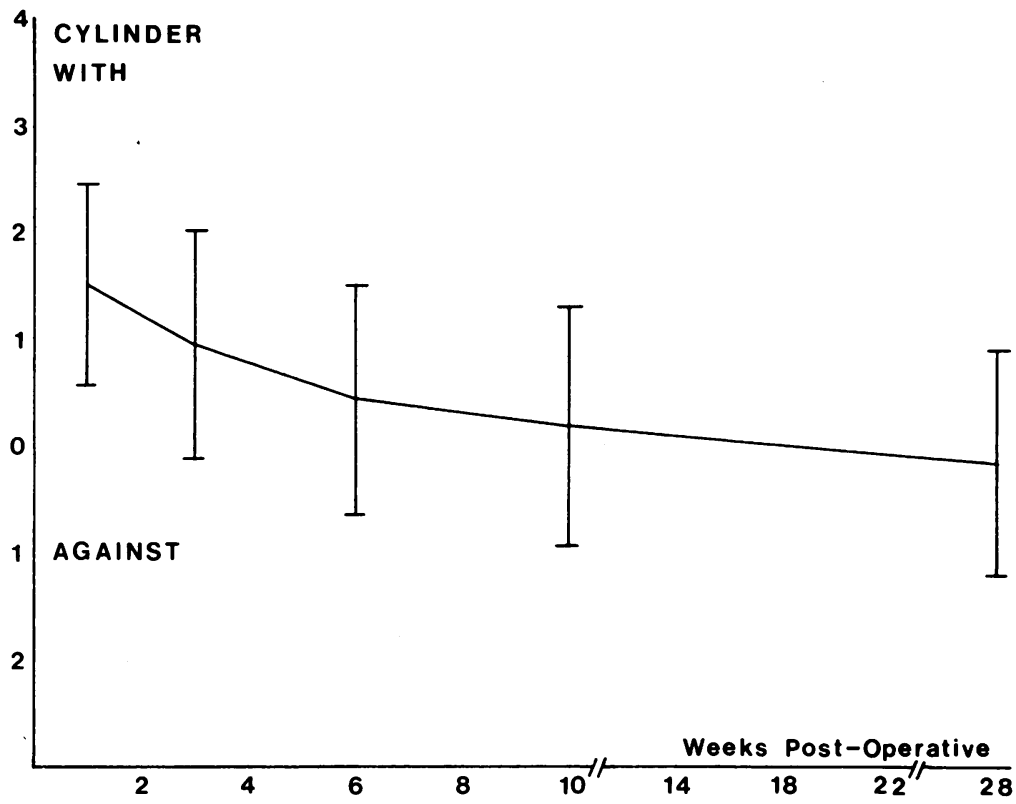

Fig. 9 Change in astigmatism with time in cases in which sutures not cut.

used to derive the expected refractive values at the required times as indicated above.

Astigmatism with the rule was found to decrease from an initial mean of $1.51 \mathrm{D}$ at week 1 to a mean of $0.18 \mathrm{D}$ at week 10 . This trend, illustrated in Fig. 9, was highly statistically significant; one-way analysis of variance yielded $p=0 \cdot 003$. From the 10 th to the 28th weeks there was a further slight reduction in with-the-rule astigmatism to a final mean of $0 \cdot 17 \mathrm{D}$ against the rule - that is, just crossing the point of zero astigmatism. There was, however, no statistical difference between the astigmatism at week 10 and that at week 28 (paired $t$ tests, $\mathrm{p}=0 \cdot 67$ ).

The postoperative IOP was correlated with neither the initial rate of astigmatic decline (correlation coefficient $=0.097$ ) nor with the total astigmatic change (correlation coefficient $=0 \cdot 152$ ).

The preoperative astigmatic error correlated weakly with final postoperative astigmatic error (correlation coefficient $=\mathbf{0} \cdot 243$ ). This is illustrated in Fig. 10. There was no signficant difference between preoperative and final postoperative astigmatic error (paired $t$ tests, $\mathrm{p}=0.746$ ). The mean preoperative error was $0.12 \mathrm{D}$ against the rule and the mean final postoperative error was $0.17 \mathrm{D}$ against the rule. The variability of the preoperative astigmatism, however, was slightly greater than the postoperative; the standard deviation preoperatively was $1.34 \mathrm{D}$ while that postoperatively was $1.05 \mathrm{D}$. These findings demonstrate that the surgical method counteracted the preoperative astigmatism.
The spherical equivalent changed postoperatively in the direction of myopia. This trend was highly statistically significant when tested against the null hypothesis that there should be no net change in spherical equivalent $\left(p<10^{-5}\right)$. This change is illustrated in Fig. 11. This finding contrasts with the fact that the negative cylindrical error at $180^{\circ}$ was decreasing.

There was a weak correlation between the IOP and the change in spherical equivalent (correlation coefficient $=0 \cdot 243$ ).

The average case was one having $1.51 \mathrm{D}$ cyl with the rule at one week, declining to zero at approximately 12 weeks, and having a final value of $0 \cdot 17 \mathrm{D}$ cyl against the rule. An eye seen at one week needing a $+1.75 \mathrm{D}$ cyl at $90^{\circ}$ should be regarded as the ideal immediate surgical result.

\section{CASES IN WHICH SUTURES CUT}

Nine cases with significant initial with-the-rule astigmatism were included in this group (Fig. 7). Individual sutures were cut in line with the plus cylinder axis as early as one week and as late as 10 weeks postoperatively. Suture cutting was repeated in two eyes. The results in the individual eyes are shown in Fig. 7. The effect was most marked when performed early. One patient appeared to show an enormous change from with-the-rule to against-therule, which has been exaggerated by the simplification in defining with and against the rule astigmatism. This patient's course was: Week 1: $-3 \cdot 50 /+5 \cdot 50$ 


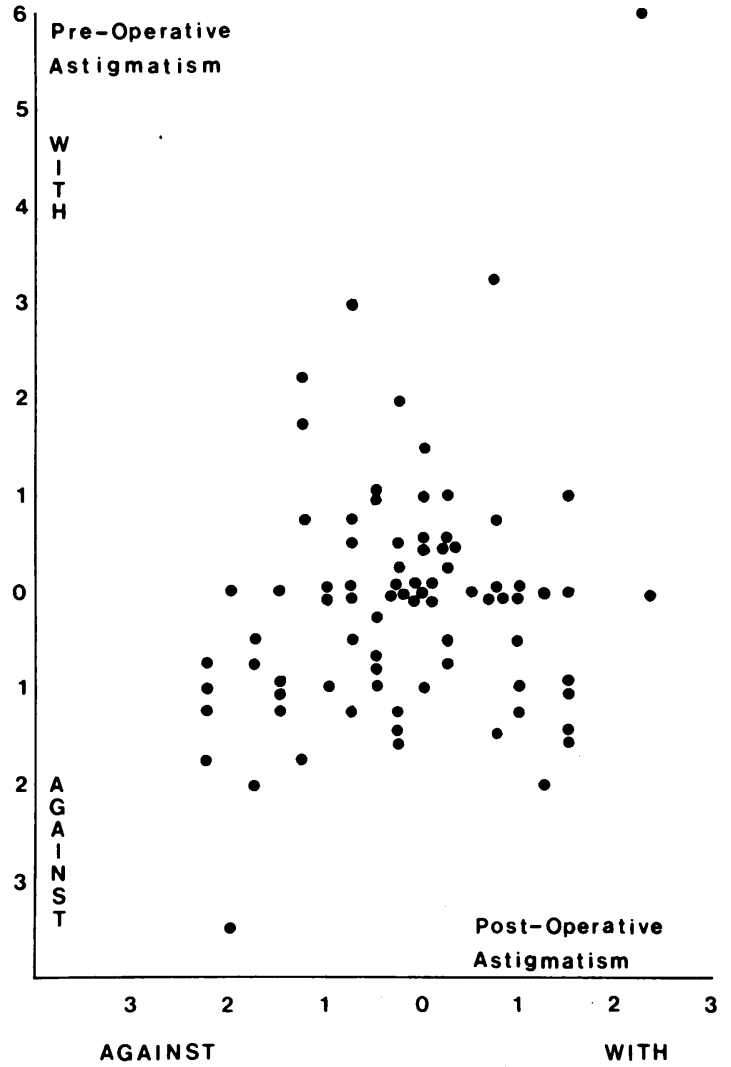

Fig. 10 Correlation between preoperative astigmatic values and final postoperative astigmatic values (all cases). $115^{\circ}$. Week 2: $-4 \cdot 00 /+4 \cdot 50115^{\circ}$; suture cut at 11 o'clock. Week 4: $-2 \cdot 00 /+4 \cdot 25140^{\circ}$. Week 6: $-2 \cdot 50 /$ $+4.50145^{\circ}$; suture cut at 10.30 o'clock. Week 10 : $-1 \cdot 00 /+2 \cdot 25160^{\circ}$. Week 18: $-1 \cdot 00 /+2 \cdot 25175^{\circ}$.

\section{Discussion}

Change in cylindrical correction is usually explained as a decrease in curvature of the vertical meridian postoperatively. If this were in fact the case, the spherical equivalent would be changing in the direction of hypermetropia. Our data show this not to be true, which means that another mechanism is operative. The most likely explanation is that the horizontal meridian is in fact steepening, and that this is the predominant effect, resulting in a myopic shift in the spherical equivalent. Other possible explanations include a forward movement of the intraocular lens implant, or an increase in the axial length of the eye, both of which seem unlikely. A study involving keratometry may shed light on the precise mechanism.

If astigmatism is to be minimised in the cataract section, greater effort is required on the part of the surgeon both peroperatively and postoperatively. Two methods of suturing emerge as superior: continuous suturing controlled by peroperative keratometry $^{14}$ or multiple limbal interrupted nylon sutures as used in the present study and by Bambery. ${ }^{5}$ The peroperative keratometry requires extra manoeuvres in the operating theatre, including raising the intraocular pressure to a normal level. ${ }^{14}$ The multiple interrupted nylon sutures with buried knots are
Fig. 11 Change in spherical equivalent error with time (uncut cases).

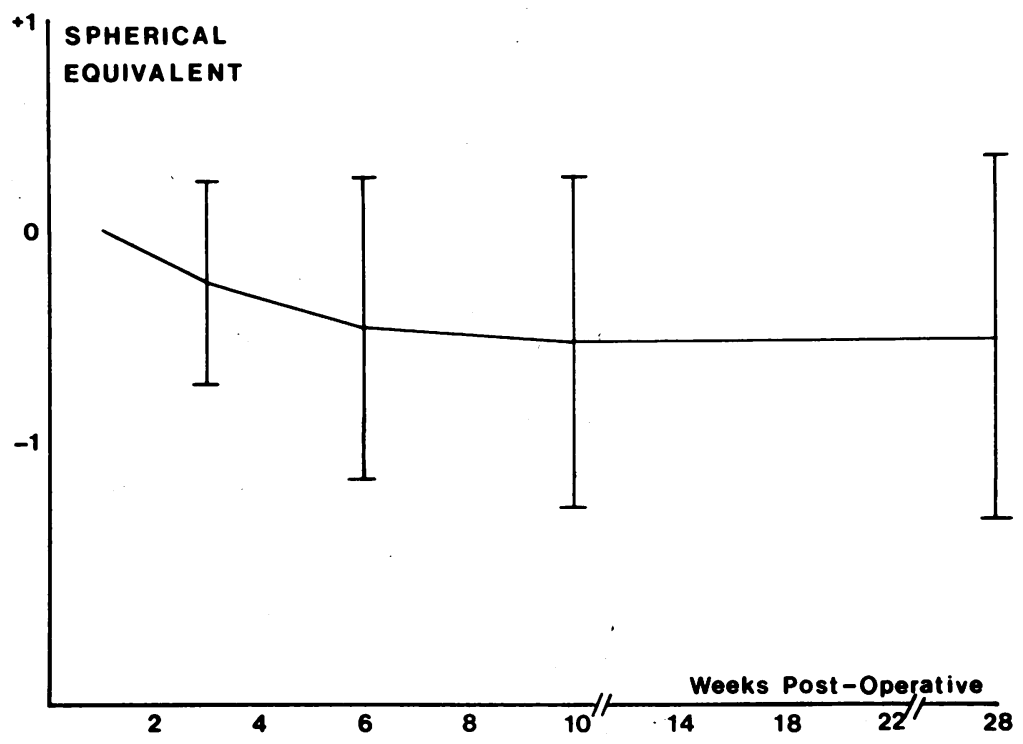


tedious to insert. It is probable that each method adds a similar amount of time to the operation. The continuous suture with keratometer control can correct for the patient's preoperative astigmatism with or against the rule. Interrupted sutures, as used in the present method, can do this too, and they can also correct a preoperative oblique astigmatism. Interrupted nylon corneal sutures are also an effective method of section closure, but produced more, surgically induced astigmatism in comparison with the same sutures inserted limbally. ${ }^{45}$

Postoperatively the surgeon has to be prepared to cut sutures. $^{1-3514162326}$ The interrupted suture offers the surgeon the best opportunity for astigmatic control by suture cutting, since individual sutures can be cut in line with the patient's plus cylinder axis, and this does not weaken the entire section. Continuous sutures may be cut,${ }^{214}$ but if this is done too early the wound becomes slack and if it is done too late it is ineffective. The continuous suture may also be adjusted by easing it towards the tight meridian. ${ }^{26}$ Our own experience suggests that the best time for cutting interrupted sutures is between one and six weeks, but others have found that later suture cutting is still effective, ${ }^{5}$ and it is inadvisable to cut continuous sutures until seven weeks. The lack of correlation between the postoperative IOP and the rate of astigmatic decline shows that this study fails to demonstrate the relevance of the IOP. However, a raised IOP was deliberately guarded against by the medical treatment used in this study, and it remains possible that an uncontrolled IOP might affect the change in astigmatism.

\section{References}

1 Jaffe NS, Clayman HM. The pathophysiology of corneal astigmatism following cataract extraction. Ophthalmology 1975; 79: $615-30$.

2 Wishart MS, Wishart PK, Gregor ZJ. Corneal astigmatism following cataract extraction. Br J Ophthalmol 1986; 70: 825-30.

3 Van Rij G, Waring GO. Changes in corneal curvature induced by sutures and incisions. Am J Ophthalmol 1984; 98: 773-83.

4 Iliff CE, Khodadoust A. The control of astigmatism in cataract surgery. Trans Am Ophthalmol Soc 1967; 65: 160-7.

5 Bambery SJ. Reduction of astigmatism following cataract surgery. Trans Ophthalmol Soc UK 1986; 105: 647-9.
6 Pearce JL. Discussion on suture material. Adv Ophthalmol 1970 22: $58-9$.

7 Moore JG. Incidence of astigmatism after cataract surgery. Comparison of continuous and interrupted sutures. Trans Ophthalmol Soc UK 1977; 97: 104-5.

8 Reading VM. Astigmatism following cataract surgery. $\mathrm{Br} J$ Ophthalmol 1984; 68: 97-104.

9 Thygesen J, Reersted P, Fledelius H, Corydon L. Corneal astigmatism after cataract extraction. A comparison of corneal and corneoscleral incisions. Acta Ophthalmol (Kbh) 1979; 57: 243-50.

10 Torchia RT, McCarthy RW. The corneal incision, a precision cataract wound. Ophthalmic Surg 1983; 14: 72-4.

11 Meredith TA, Maumenee AE. A review of one thousand cases of intracapsular cataract extractions. II: Visual results and astigmatic analysis. Ophthalmic Surg 1979; 10: 42-5.

12 Singh D, Kumar, K. Keratometric changes after cataract extraction. Br J Ophthalmol 1976; 60: 638-41.

13 Rowan PJ. Corneal astigmatism following cataract extraction. Ann Ophthalmol 1978; 10: 231-4.

14 Amoils SP. Intraoperative keratometry with the oval comparator (astigmometer). Br J Ophthalmol 1986; 70: 708-11.

15 Hyde LL, Maumenee AE. The double shoelace cross-tied suture. In: Emery JA, Paton D, eds. Current concepts in cataract surgery. Selected proceedings of the fourth Biennial Cataract Surgical Congress. Philadelphia: Mosby, 1976: 62.

16 Stainer GA, Binders PS, Packer WT, Perl T. The natural and modified course of post cataract astigmatism. Ophthalmic Surg 1982; 13: 822-7.

17 Troutman RC, Kelly S, Kaye D, Clahane AC. The use and preliminary results of the Troutman surgical keratometer in cataract and corneal surgery. Ophthalmology 1977; 83: 232-8.

18 Terry CM. Introduction to a surgical keratometer. In: Emery JM, Jacobson AC, eds. Current concepts in cataract surgery. Selected proceedings of the sixth Biennial Cataract Surgical Congress. St Louis: Mosby, 1980: 27-9.

19 Terry CM. Surgical keratometry and optics of corneal alteration In: Schacher RA, Levy NS, Schacher L, eds. Keratorefraction. Texas: Denison, 1980: 15-25.

20 Colvard DM, Kratz RP, Mazzocco TR, Davidson B. Clinical evaluation of the Terry surgical keratometer. J Am Intraocul Implant Soc 1980; 6: 249-51.

21 Colvard DM, Kratz RP, Mazzocco TR, Davidson B. The Terry surgical keratometer: a 12 month follow-up report. $J A m$ Intraocul Implant Soc 1981; 7: 348-50.

22 Samples JR, Binder PS, Earl K. The value of the Terry keratometer in predicting postoperative astigmatism. Ophthal mology 1984; 91: 280-4.

23 Perl T, Binder PS, Earl K. Post cataract astigmatism with and without the use of the Terry keratometer. Ophthalmology 1984 91: 489-93.

24 Jolson AS, Seidl FJ. Post-operative astigmatism induced by intraocular lens tilt. J Am Intraocul Implant Soc 1984; 10: 213-4.

25 Moore JG. Intraocular implants: the postoperative astigmatism Br J Ophthalmol 1980; 64: 318-21.

26 Roper-Hall MJ. The control of astigmatism after surgery and trauma. Br J Ophthalmol 1982; 66: 556-9.

Accepted for publication I May, 1987. 